\title{
Influência da Educação Física Adaptada inclusiva no desenvolvimento global de uma criança com deficiências multiplas durante três anos
}

\author{
Influence from Adapted Physical Education in the global \\ development of a child with multiple disabilities during three years
}

\author{
Beatriz Dittrich Schmitt', Angela Teresinha Zuchetto', John Peter Nasser
}

'Universidade Federal de Santa Catarina (UFSC), Florianópolis, SC, Brasil

Recebido em: 31/03/2016 / Aceito em: 20/04/2016

beatriz_bds@hotmail.com

\section{RESUMO}

Objetivo: analisar, durante três anos, as adequações necessárias, as interações sociais e o tempo de engajamento de uma criança com encefalopatia crônica não evolutiva e surdez profunda em aulas de Educação Física Adaptada (AMA/CDS/UFSC). Método: pesquisa longitudinal, em que as aulas foram filmadas e ocorreram em dois encontros semanais com uma hora de duração. Foram ministradas 149 aulas, durante os três anos, sendo seis selecionadas intencionalmente (duas por ano). Para coleta de dados, realizou-se registro cursivo através das filmagens, com especial atenção nas matrizes de análises: a) Tempos das aulas (total, transição, de atividades); b) Tempos de engajamento aluno (desperdício, fora de foco, engajamento); c) Adequações necessárias; d) Interações sociais. Realizou-se análise quantitativa e qualitativa. Resultados: os tempos das aulas variaram, ocorrendo 10 minutos de diferença entre as aulas, com maior e menor duração. As aulas com grandes períodos de transição reduziram o tempo reservado à realização das atividades. 0 tempo de engajamento do aluno também variou, pois as atividades propostas e o fornecimento de auxílio implicam seu engajamento. Já, as adequações englobam materiais adaptados ou auxílio pessoal, assim, os profissionais interagem a fim de auxiliá-lo e o aproximam dos seus colegas. Os pares o auxiliaram e motivaram, mas também demonstraram afeto, beijando-o e segurando suas mãos. Considerações finais: ao longo dos três anos, observaram-se melhoras motoras e cognitivas. 0 aluno compreendeu dinâmica de atividades, a partir de repetição e observação. Também passou a expressar vontades com maior facilidade, apontando para pessoas/lugares e manuseando a cadeira de rodas sozinho.

Palavras-Chave: Criança com Deficiência; Educação Física; Desenvolvimento Infantil.

\section{ABSTRACT}

Objective: analyze for three years the necessary adaptations, social interactions and engagement time of a child with non-progressive chronic encephalopathy and profound deafness, in Adapted Physical Education classes (AMA/CDS/UFSC). Method: longitudinal study, lessons were videotaped in two weekly meetings of one hour long. 149 classes were taught during the analyzed period (three years), and six were intentionally selected (two per year). For data collection, it was used a cursive record through the shootings, with special attention to the matrices analysis: a) Length pf classes time (total, transition and activities); b) Student engagement time (waste, out of focus and engagement), c) Necessary adjustments; d) Social interactions. Quantitative and qualitative analysis were performed. Results: duration time of classes varied, with 10 minute apart among classes with greater and lesser length. Classes with large transition periods reduced the time allocated to perform activities. The student engagement time also varied, since proposed activities and provision of help implied his engagement. As for adjustments they include adapted materials or personal help, thus the professionals interact in order to help and approach him from colleagues. The classmates help and motivate him, but they also show affection by kissing and hol- 
ding his hands. Closing remarks: there were motor and cognitive improvements over three years. The student understood the activities dynamics from repetition and observation. Also, he started to express his wills with greater ease, pointing to people/places and handling alone the wheelchair.

Keysword: Child with Disabilities; Physical Education; Child Development.

\section{INTRODUÇÃO}

A encefalopatia crônica não evolutiva (ECNE) faz parte de um grupo de distúrbios permanentes, de caráter não progressivo causado por lesão cerebral, que pode ocorrer antes, durante ou após o nascimento, comprometendo o sistema nervoso central. ${ }^{1-4}$ Caracteriza-se pela dificuldade de controlar funções motoras e interfere no desenvolvimento global da criança. ${ }^{2}$ Os distúrbios motores são frequentemente acompanhados por deficiências de cognição, percepção, comunicação e sensação, conforme a área cerebral afetada pela lesão. ${ }^{1,2,4-6}$

Salienta-se que crianças com ECNE têm maior propensão à diminuição do sucesso social, quando comparadas aos seus pares sem deficiência e, em parte, pode-se atribuir esse insucesso a impactos causados pelos atributos pessoais do infante, pelo comprometimento motor e/ou intelectual ou, ainda, por fatores ambientais, ocasionando restrições nas interações sociais. ${ }^{7-11}$

Os jovens com deficiência também tendem a ser menos ativos fisicamente e mais suscetíveis ao sedentarismo do que seus pares sem deficiência e, apesar de serem incluídos nas aulas, não recebem a mesma quantidade de atividade física. ${ }^{12-15}$ Nesse aspecto, é importante que as pessoas com deficiência, inclusive crianças com ECNE, pratiquem atividades físicas adequadas às suas possibilidades e que, em consequência, Ihes propiciem benefícios biopsicossociais. ${ }^{16-20}$ Com isso, os profissionais devem conhecer a criança e suas possibilidades para implementarem as adequações necessárias para assegurar sua participação, promovendo seu desenvolvimento global. ${ }^{18-20}$

Além disso, atualmente, para as crianças, recomenda-se um período de 30 a 60 minutos de atividade física de intensidade moderada, na maioria dos dias da semana. ${ }^{14}$ Por essa razão, tanto a otimização de tempo, como o planejamento prévio das aulas podem proporcionar maior engajamento das crianças nas atividades. ${ }^{18,20}$

Com base nessas considerações, essa pesquisa teve como objetivo analisar, durante três anos consecutivos, as adequações necessárias, as interações sociais e o tempo de engajamento de uma criança com encefalopatia crônica não evolutiva (ECNE) mista e surdez profunda, participante em um programa de Atividade Motora Adaptada.

\section{MÉTODO}

\section{Estratégia de pesquisa}

Essa pesquisa (estudo de caso) se caracteriza como descritiva, qualitativa e longitudinal; foi aprovada pelo Comitê de Ética da Universidade Federal de Santa Catarina, sede do programa de Atividade Motora Adap- tada (AMA), sob o processo $\mathrm{n}^{\circ}$. 911/10. Os responsáveis pelo participante assinaram o termo de consentimento livre e esclarecido.

\section{Os contextos da pesquisa}

\section{O Programa de Atividade Motora Adaptada}

O Programa de Atividade Motora Adaptada - AMA - é oferecido pelo Departamento de Educação Física do Centro de Desportos da Universidade Federal de Santa Catarina (DEF/CDS/UFSC), gratuitamente, desde 1995. O objetivo do programa se relaciona com a tríade: ensino-pesquisa-extensão. Assim, oferece atividades motoras adaptadas a pessoas com deficiências (extensão), oportuniza vivências práticas aos graduandos do curso de Educação Física (ensino/formação) e desenvolve estudos nessa área (pesquisa). As atividades propostas ocorrem em dois encontros semanais, com duração média de 1 hora, um no solo e outro na água, durante um período de três anos. ${ }^{17}$

Os acadêmicos matriculados na disciplina de Educação Física Adaptada, antes de realizarem as vivências práticas no AMA, de acordo com Zuchetto ${ }^{17}$ devem aprender a apreender por meio do que chamamos "exercícios de aprendizagem". Aprender a olhar o deficiente como pessoa, descobrir suas possibilidades, buscar na pessoa o que ela já sabe, como sabe, o que ela tem, assim, compete aos acadêmicos elaborarem as atividades, junto com a professora responsável e ministrá-las. ${ }^{17}$ No início do semestre letivo, os acadêmicos são divididos em três módulos para que se insiram nas aulas, gradativamente, mantendo a proporção de um adulto por criança com deficiência, considerada ideal no programa. ${ }^{18,19}$

\section{As Aulas}

Durante os três anos consecutivos analisados, foram ministradas 149 aulas no solo. Dentre elas, foram intencionalmente selecionadas seis aulas - duas a cada ano - em que os pré-requisitos foram: a) presença do aluno; b) otimização da gestão do tempo de aula pelo ministrante; c) proporção de um acadêmico auxiliar para cada criança presente. No que tange às aulas escolhidas, é importante caracterizá-las quanto à quantidade de aulas ministradas, ao número de participantes (crianças e adultos) e atividades propostas, conforme mostra a Tabela 1.

Tabela 1 - Características das aulas.

\begin{tabular}{lccc}
\hline Semestres & $\begin{array}{c}\mathbf{N}^{\circ} \text { total de aulas } \\
\text { no período analisado }\end{array}$ & $\begin{array}{c}\mathbf{N}^{\circ} \text { Crianças } \\
\text { nas aulas }\end{array}$ & $\begin{array}{c}\mathbf{N}^{\circ} \text { Adultos } \\
\text { nas aulas }\end{array}$ \\
\hline Semestre I & 19 & 11 & 18 \\
Semestre II & 29 & 14 & 34 \\
Semestre III & 30 & 11 & 15 \\
Semestre IV & 27 & 08 & 07 \\
Semestre V & 26 & 11 & 15 \\
Semestre VI & 18 & 10 & 09 \\
\hline Número Total & 149 & 65 & 98 \\
\hline
\end{tabular}

\section{O Participante}

A escolha do participante foi intencional por se tratar de uma criança do sexo masculino com deficiências múltiplas (deficiência física do tipo ECNE mista e surdez profunda), originada no período pré-natal, o qual contava 
com 11 anos de idade no início da pesquisa e é participante assíduo do Programa AMA.

No que se refere às características pessoais, apresenta triplegia, locomove-se por meio de cadeira de rodas e fica em pé com auxílio de terceiros. Comunica-se através de expressões faciais que indicam aprovação ou desaprovação, aponta para indicar seus interesses e observa os acontecimentos ao seu redor.

\section{Coleta de dados}

Para a coleta de dados, as aulas foram previamente planejadas e, ato contínuo, ministradas. Durante a ministração, fez-se a filmagem dos encontros e, desse modo, foi possível realizar o registro cursivo, isto é, análise minuciosamente descritiva minuto a minuto, a fim de verificar o tempo de engajamento do aluno, as interações sociais e as adequações necessárias. Recorreu-se, ainda, ao banco de dados do programa com o propósito de caracterizar o aluno, a partir de entrevista semiestruturada com seu responsável e selecionar as aulas, atendendo aos pré-requisitos estabelecidos.

\section{Instrumentos para a coleta de dados}

Os materiais necessários para a filmagem das aulas foram: um tripé, uma câmera filmadora, uma bateria recarregável e um cartão de memória. As imagens foram baixadas, convertidas e, em seguida, gravadas em DVD para que pudessem ser feitos os registros cursivos.

\section{Análise dos dados}

Os dados foram analisados de forma descritiva, apropriando-se de métodos qualitativos e quantitativos, considerando-se as filmagens das aulas e os registros cursivos. Destaca-se que as matrizes de análises dessa pesquisa foram: os tempos das aulas e os tempos de engajamento do aluno, o comportamento social e as adequações necessárias.

\section{Tempos da aula e engajamento do aluno}

Para análise dos tempos da aula e do engajamento, utilizou-se o modelo adaptado para o contexto do AMA, ${ }^{20-22}$, apresentado no Quadro 1.

\section{Comportamento social}

As interações sociais foram quantificadas e quali- ficadas, através de uma matriz de análise denominada Sociograma, onde identificam-se, a partir das filmagens das aulas, todas as relações sociais que envolvem a criança observada e seus pares com deficiência ou adultos. ${ }^{23}$ Vale destacar que essas interações podem partir, tanto da própria criança, quanto dos demais participantes. ${ }^{11}$

\section{Adequações}

As adequações necessárias para possibilitar o envolvimento da criança nas aulas foram identificadas por meio de uma matriz de análise proposta por Zuchetto. ${ }^{23}$ Através desse artifício metodológico, é possível verificar a capacidade do sujeito em realizar as atividades, principais dificuldades e a necessidade de auxílio pessoal e de objetos durante as tarefas. ${ }^{19}$

\section{RESULTADOS E DISCUSSÃO}

Como parte de um estudo maior, os participantes das aulas analisadas variaram em cada semestre, bem como a quantidade de crianças, acadêmicos e bolsistas presentes, conforme apresentado na Tabela 1. Destaca-se que as crianças não foram as mesmas nas aulas analisadas e que nas aulas dos Semestres I, II e III havia uma criança sem deficiência presente, irmã de alunos com deficiência engajados no AMA. Em contrapartida, nas aulas dos Semestres IV, V e VI não havia nenhuma criança sem deficiência.

Todas as aulas analisadas mantiveram, no mínimo, a proporção de um adulto para acompanhar cada criança. ${ }^{18,19,21}$ A aula do Semestre II teve maior proporção, sendo 34 adultos para 13 crianças. Vale ressaltar que, na aula do Semestre VI, o pai do aluno (sujeito de nosso estudo) atuou como auxiliar a fim manter a proporção ideal.

As atividades propostas nas aulas incorporaram parâmetros fundamentados na abordagem desenvolvimentista e, assim, as atividades selecionadas atuam como mediadoras entre as duas dimensões do desenvolvimento humano: a individualidade e a sociabilidade. ${ }^{17}$ Nesse sentido, as temáticas das atividades foram: a) atividades de baixa organização; b) atividades pré-esportivas; c) atividades rítmicas; d) atividades de postura e locomoção; e) atividades de autocontrole. ${ }^{24}$

Quadro 1 - Modelo dos tempos das aulas e do engajamento do aluno.

\begin{tabular}{|c|c|c|}
\hline & Modalidade de Tempo (T) & Definição \\
\hline \multirow{3}{*}{ 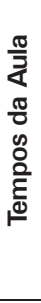 } & T. total da aula & $\begin{array}{l}\text { Quantidade de tempo que o professor realmente gasta no assunto, tarefa ou ativi- } \\
\text { dade específica; }\end{array}$ \\
\hline & T. de transição & $\begin{array}{l}\text { Intervalo existente entre as atividades, incluindo-se a duração que se levou para } \\
\text { começar a aula (chegada, organização da turma e explicação da primeira atividade), } \\
\text { mudança de atividade (organização, explicação e demonstração da tarefa) e, no fi- } \\
\text { nal da aula, a despedida, quando se cumprimentam para retornarem aos seus lares; }\end{array}$ \\
\hline & T. em atividade & $\begin{array}{l}\text { Resulta da diminuição do tempo total da aula com o tempo de transição (Ex.: T. } \\
\text { total da aula }- \text { T. de Transição }=\text { T. em atividade); }\end{array}$ \\
\hline \multirow{3}{*}{ 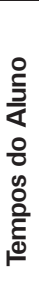 } & T. fora de foco & É o tempo em que o participante não aparece nas cenas da filmagem; \\
\hline & T. em ocupação & $\begin{array}{l}\text { Quantidade de tempo que os alunos realmente gastam numa atividade ou tarefa. } \\
\text { Este tipo de tempo é medido em termos de tempo na tarefa ou fora da tarefa. Se um } \\
\text { professor atribui tempo para os alunos resolverem problemas de matemática no lugar e } \\
\text { o aluno está a trabalhar nesses problemas, o comportamento do aluno é na tarefa. Do } \\
\text { contrário, se o aluno faz rabiscos o comportamento é contado como fora da tarefa; }\end{array}$ \\
\hline & T. em desperdício & $\begin{array}{l}\text { Tempo em que o aluno deixa de executar a atividade proposta porque se distrai } \\
\text { realizando outras ações não solicitadas pelo professor. }\end{array}$ \\
\hline
\end{tabular}


Ao se discutir os primeiros objetivos dessa pesquisa, disponibilizam-se os dados obtidos, a partir da análise dos tempos das aulas através da Tabela 2.

Percebe-se que as aulas analisadas durante os três anos apresentam diferenças no tempo total de aula, no tempo de transição e no tempo em atividade. Com base na Tabela 2, destacam-se aspectos interessantes: a aula com maior duração de tempo foi no Semestre II e a aula com menor tempo de duração foi no Semestre IV, as quais tiveram aproximadamente dez minutos de diferença. As aulas com menor e maior tempos de transição ocorreram nos Semestres I e II, respectivamente. A aula do Semestre I teve maior tempo para a realização das atividades e a aula do Semestre IV teve menor tempo.

Durante os momentos das transições, os ministrantes explicaram e demonstraram as atividades, organizaram a disposição dos alunos e distribuíram os materiais necessários. No que se refere à criança, nesses momentos, olhou em direção às explicações e demonstrações, observou a organização dos ministrantes, embora, em alguns momentos, aparentou estar disperso. Salienta-se que, apesar de as transições não fazerem parte das atividades, são momentos importantes, porque a criança pode interagir com seus pares e/ ou acadêmicos. Além disso, bateu palmas, sorriu, movimentou a cadeira de rodas sozinho e recebeu auxílio para atender às solicitações dos ministrantes.

A partir dos tempos das atividades propostas, é possível analisar os tempos de engajamento do aluno conforme mostra a Tabela 3.

O tempo de engajamento do aluno variou nas aulas analisadas. Assim, destaca-se que permaneceu maior e menor tempo fora de foco, nas aulas dos Semestres II e III, respectivamente. Também foi na aula do Semestre II que a criança permaneceu menor tempo em ocupação enquanto, na aula do Semestre $V$, permaneceu maior tempo em ocupação. No que se refere ao tempo em desperdício, as aulas dos Semestres IV e V se destacaram por terem tempos com maior e menor desperdício, respectivamente.

Em razão das características próprias da criança, entende-se que as atividades propostas podem facilitar ou dificultar seu engajamento. Constatou-se que, nas aulas dos Semestres I, II, III e IV; as atividades com música não o mantiveram interessado, tendo em vista que seu tempo de engajamento foi sensivelmente inferior. Enquanto nas aulas dos Semestres V e VI, as atividades com música passaram a despertar seu interesse, pois nos semestres anteriores já havia vivenciado essas brincadeiras. Além disso, a coreografia específica de cada atividade foi seguida conforme a letra da música e, ao término de cada canção, reiniciava-se a atividade desde a primeira estrofe e, por meio dessas repetições, facilitou-se o processo de aprendizagem. ${ }^{25-28}$

Outro aspecto relevante foram os benefícios motores e a forma de comunicação obtidos a partir da prática regular de atividade física. A criança indicou compreensão das tarefas mediante observação e passou a exprimir seus desejos com mais facilidade, pois apontava para lugares e pessoas com os quais gostaria de estar, bem como manuseava sua cadeira de rodas com maior frequência e autonomia. Desse modo, conquistou maior autonomia para se engajar nas atividades propostas; participou por observação quando não recebia auxílio, divertindo-se ao ver seus colegas executarem as tarefas e aprendendo a partir dessas demonstrações. O aluno, que não ouve, imitou seus colegas e, com isso, assimilou os conteúdos abordados em sala de aula. Evidenciando a importância de que toda explicação deve ser seguida de demonstração. ${ }^{26}$

Da análise da Tabela 3, observa-se que não houve desenvolvimento linear nos tempos de engajamento ao longo dos três anos semestres. Isso significa que o tempo em ocupação não foi crescente a cada aula, assim como o tempo em desperdício não foi decrescente, conforme seria o ideal. Os motivos que explicam o intervalo de tempo da criança fora de foco foram variados. Nas atividades em círculo e naquelas mais agitadas, não é possível filmar todos simultaneamente (em decorrência da amplitude do raio de abrangência da câmera e da dinâmica das atividades). Salienta-se que, apesar de estar fora de foco, a criança pode realizar as atividades propostas. Por outro lado, as razões que implicam desperdício foram: não recebimento de auxílio; não olhar em direção às atividades, explicações e demonstrações (olhava para o espelho ou para outras crianças e brincava com uma bola com guizo); acadêmicos procuravam a melhor maneira de auxiliá-lo e posicioná-lo fora da cadeira de rodas para caminhar e rolar. A criança ficou em ocupação não só porque participou por observação, mas também bateu palmas inúmeras vezes, apresentando expressões de divertimento e porque recebeu auxílio para se engajar nas atividades.

Contudo, há outros fatores relacionados ao en-

Tabela 2 - Tempos das aulas analisadas

\begin{tabular}{|c|c|c|c|c|c|c|}
\hline Tempos & $\begin{array}{c}\text { Semestre } \\
\text { I }\end{array}$ & $\begin{array}{c}\text { Semestre } \\
\text { II }\end{array}$ & $\begin{array}{c}\text { Semestre } \\
\text { III }\end{array}$ & $\begin{array}{c}\text { Semestre } \\
\text { IV }\end{array}$ & $\begin{array}{c}\text { Semestre } \\
\text { V }\end{array}$ & $\begin{array}{c}\text { Semestre } \\
\text { VI }\end{array}$ \\
\hline Total & $49^{\prime} 44^{\prime \prime}$ & $51^{\prime} 59^{\prime \prime}$ & $43^{\prime}$ & $41^{\prime} 15^{\prime \prime}$ & $48^{\prime} 58^{\prime \prime}$ & $49^{\prime} 47^{\prime \prime}$ \\
\hline Transição & $06^{\prime} 56^{\prime \prime}$ & $15^{\prime} 11^{\prime \prime}$ & $09^{\prime} 02^{\prime \prime}$ & 07'06'" & $08^{\prime} 6^{\prime \prime}$ & $11^{\prime} 42^{\prime \prime}$ \\
\hline Atividades & $42^{\prime} 48^{\prime \prime}$ & $36^{\prime} 48^{\prime \prime}$ & $33^{\prime} 58^{\prime \prime}$ & $34^{\prime} 09^{\prime \prime}$ & $40^{\prime} 52^{\prime \prime}$ & $38^{\prime} 05^{\prime \prime}$ \\
\hline
\end{tabular}

Tabela 3 - Tempos de engajamento do aluno.

\begin{tabular}{|c|c|c|c|c|c|c|}
\hline Tempos & $\begin{array}{c}\text { Semestre } \\
\text { I }\end{array}$ & $\begin{array}{c}\text { Semestre } \\
\text { II }\end{array}$ & $\begin{array}{c}\text { Semestre } \\
\text { III }\end{array}$ & $\begin{array}{c}\text { Semestre } \\
\text { IV }\end{array}$ & $\begin{array}{c}\text { Semestre } \\
\text { V }\end{array}$ & $\begin{array}{c}\text { Semestre } \\
\text { VI }\end{array}$ \\
\hline Fora de Foco & $12^{\prime} 43^{\prime \prime}$ & $18^{\prime} 53^{\prime \prime}$ & $05^{\prime} 03^{\prime \prime}$ & $06^{\prime} 34^{\prime \prime}$ & $10^{\prime} 58^{\prime \prime}$ & $07^{\prime} 15^{\prime \prime}$ \\
\hline Ocupação & $24^{\prime} 55^{\prime \prime}$ & $13^{\prime} 23^{\prime \prime}$ & $23^{\prime} 26^{\prime \prime}$ & $15^{\prime} 12^{\prime \prime}$ & $26^{\prime} 27^{\prime \prime}$ & $24^{\prime} 25^{\prime \prime}$ \\
\hline Desperdício & $5^{\prime} 10^{\prime \prime}$ & $4^{\prime} 32^{\prime \prime}$ & $05^{\prime} 29^{\prime \prime}$ & $12^{\prime} 23^{\prime \prime}$ & $3^{\prime} 27^{\prime \prime}$ & $06^{\prime} 25^{\prime \prime}$ \\
\hline
\end{tabular}


gajamento do aluno como, por exemplo, a proporção de adultos para cada criança, o preparo do profissional para lidar com a criança, as atividades propostas e as adequações necessárias. Nesse sentido, vale destacar que, em todas as aulas analisadas, a proporção foi igual ou maior do que um adulto por criança. Quando dois acadêmicos auxiliam a criança, possibilitam que participe efetivamente das atividades e, por vezes, participa sem utilizar a cadeira de rodas.

Por outro lado, mais importante do que a proporção entre crianças e adultos é a capacitação e o treinamento desses profissionais a fim de que sejam oferecidos serviços de apoio adequados aos alunos com deficiência. ${ }^{28,29}$

Nessa pesquisa, todos os acadêmicos participantes estão em processo de formação como descrito anteriormente. Assim, os acadêmicos passam a conhecer a criança e a reconhecer suas possibilidades, identificando qual suporte será necessário a cada uma delas. ${ }^{17,28,29}$ Essas adequações fornecidas pelos acadêmicos implicam o engajamento efetivo do aluno nas atividades e podem ser fornecidos sob a forma de equipamentos adaptados como, por exemplo, bolas mais leves e cestas mais baixas. ${ }^{30} \mathrm{O}$ auxílio também pode ser fornecido pelos próprios acadêmicos, que o possibilitam experimentar e realizar as atividades sem utilização da cadeira de rodas e, para tanto, o auxílio fornecido é mais intenso a fim de mantê-lo na posição de pé. Então, percebeu-se que nas aulas dos Semestres II, IV e VI, as atividades que necessitaram de maior quantidade de adequações foram os circuitos em razão das habilidades motoras requeridas.

Deve-se ressaltar que os acadêmicos posicionaram o corpo do infante de maneira cuidadosa, visando seu bem-estar. Também, inibiram seu padrão motor flexor nos membros superiores e recorreram a "sacudidas", para chamar sua atenção. Com frequência, observou-se que os acadêmicos optaram por ficar de frente para a criança e posteriormente apontaram para onde deveria olhar, por exemplo, em direção das explicações e demonstrações.

As adequações necessárias que ocorreram em maior intensidade, durante as aulas analisadas foram: posicionar suas mãos para fazê-lo segurar bola, tecido ou arco; conduzi-lo a fazer os gestos referentes às músi- cas, segurando no seu antebraço e/ou mãos; conduzi-lo a bater palmas e motivá-lo a bater palmas sozinho (mostrar que seus pares também fazem). Destaca-se que as adequações diretamente relacionadas ao comprometimento motor da criança foram: utilizar bolas mais leves, murchas e/ou com guizo; empurrar sua cadeira de rodas (fazê-lo pegar/fugir, retornar para o círculo); tirá-lo da cadeira de rodas para mantê-lo na posição em pé e, em seguida, auxiliá-lo na marcha, fazendo-o alternar as passadas e descruzando-Ihe as pernas quando necessário; auxiliá-lo a rolar, posicionando seus braços/pernas e impulsionando o quadril e ajudá-lo a levantar, sentar e deitar; fornecer apoio nas costas para mantê-lo na posição sentado.

Além das adequações fornecidas, os acadêmicos e bolsistas também realizaram tarefas de autocuidado como, por exemplo, limpar sua boca. Na aula do Semestre VI, em alguns momentos, a criança demonstrou que não queria que sua boca e/ou nariz fossem limpos e, por isso, virou o rosto para a direção oposta e também tentou afastar a mão dos adultos de seu rosto. Fica nítido que esse fato ilustra as melhoras motoras obtidas a partir da prática regular de atividade física, relatadas nos estudos de Rimmer ${ }^{31}$, Maher et al. ${ }^{32}$ e Smits et al. ${ }^{33}$ Afinal, a prática de atividade física traz benefícios a todos seus praticantes e, em especial, a crianças com deficiência. ${ }^{32,34}$

No que tange à temática das interações sociais, enfatiza-se que, a partir da quantificação dos dados encontrados, existem diferenças numéricas entre as aulas analisadas. A Figura 1 apresenta os valores de todas as interações ocorridas nas aulas.

Conforme a Figura 2, nota-se que, a aula do Semestre $V$ teve maior quantidade de interações sociais ( $n=158$ ) e a aula do Semestre VI teve menor quantidade de interações sociais $(n=65)$. Nas aulas dos Semestres I, III, e V, a quantidade de interações foi maior do que nas aulas ocorridas nos Semestres II, IV e VI, atentando-nos para o fato de que as aulas com maior quantidade de interações ocorreram no primeiro semestre de cada ano. Constatando-se, assim, que a quantidade de interações não foi crescente à medida que as aulas foram realizadas. Destaca-se também que a aula com mais participantes presentes não obteve a

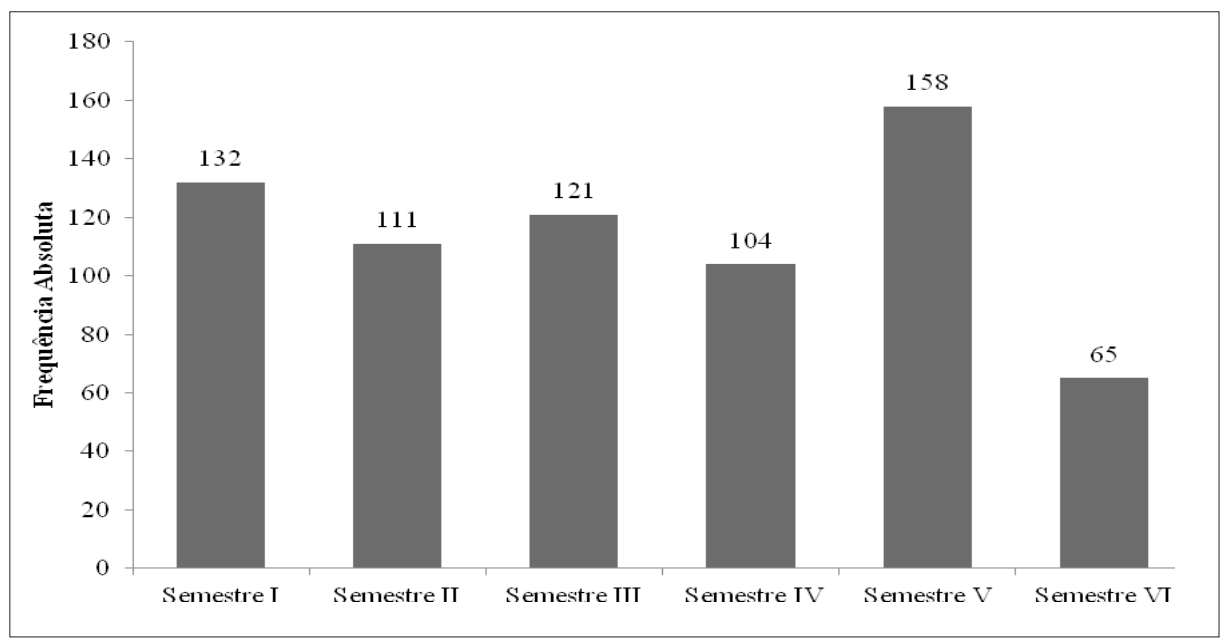

Figura 1 - Quantidade total de interações ocorridas nas aulas. 
maior quantidade de interações, assim como a aula com menos participantes não foi a aula com menor quantidade de interações sociais.

Durante a aula, a criança pode interagir com todos os participantes presentes, sejam com adultos (acadêmicos, bolsistas, ministrantes e coordenadora) ou com outras crianças. A Tabela 4 mostra a quantificação das interações sociais, ocorridas entre a criança e os demais participantes das aulas.

Faz-se necessário especificar que as interações que partiram da própria criança em direção a seus pares ou adultos oscilou nas aulas analisadas, bem como as interações que partiram dos adultos em direção à criança. A Figura 2 ilustra essa informação.

Primeiramente, é de grande valia esclarecer que a qualidade dessas interações se modificou ao longo dos semestres analisados. Afinal, a criança se fez compreender com maior facilidade, pois obteve melhoras motoras e, além disso, os acadêmicos e seus pares o conheceram e passaram a compreender sua maneira de se comunicar e se expressar por meio de gestos e olhares. Dessa maneira, a criança interagiu com seus pares por estar interessado no que faziam (corriam, saltavam e dançavam) e, por outro lado, interagiu com os adultos em razão da atividade proposta ou simplesmente para brincar, apesar de se afastar da tarefa solicitada pelo(s) ministrante(s). Por sua vez, os pares interagiram com a criança em decorrência da atividade para vê-lo realizar as tarefas, auxiliá-lo e escolhê-lo quando a atividade exigia ou simplesmente para demonstrar carinho. Já, os adultos interagiram com a criança para fornecer os auxílios necessários, motivá-lo, explicar e demonstrar as atividades, chamar sua atenção, em resposta às suas interações e realizar tarefas de autocuidado.

No que se refere aos participantes presentes nas aulas, nem sempre foram os mesmos. No entanto, evidenciou-se que os acadêmicos que mais interagiram com a criança foram os que a acompanharam durante as aulas. A explicação para isso é que grande parte dessas interações foi dedicada ao fornecimento de auxílio, a fim de possibilitar o engajamento da criança nas atividades propostas.

Quanto aos pares, apesar de não terem sido os mesmos, verificou-se que interagiram com a criança e demonstraram que, com o passar dos anos, desenvolveram o senso de auxiliá-lo nas aulas, às vezes conduzindo-o para as atividades, outras vezes motivando-o ou ainda chamando a atenção dos acadêmicos para que auxiliassem seu colega. Esse fenômeno foi observado em crianças com deficiência física do tipo ECNE com ou sem comprometimento cognitivo (aulas dos Semestres IV e VI) e também em crianças com Síndrome de Down e com deficit de atenção e hiperatividade (aulas dos Semestres I, II, III, V). Dessa maneira, evidencia-se a importância dos laços de amizade. Os colegas perceberam que precisam de auxílio e o fornecem, oportunizando seu engajamento. Esses momentos mostram o quanto as matrizes de análise das adequações e do tempo estão relacionadas, formando díades interpessoais. ${ }^{17}$

Isso evidencia que os pares buscam a criança em

Tabela 4 - Número de interações sociais ocorridas nas aulas.

\begin{tabular}{|c|c|c|c|c|c|c|}
\hline Interações Sociais & $\begin{array}{c}\text { Semestre } \\
\text { I }\end{array}$ & $\begin{array}{c}\text { Semestre } \\
\text { II }\end{array}$ & $\begin{array}{c}\text { Semestre } \\
\text { III }\end{array}$ & $\begin{array}{c}\text { Semestre } \\
\text { IV }\end{array}$ & $\begin{array}{c}\text { Semestre } \\
\text { V }\end{array}$ & $\begin{array}{c}\text { Semestre } \\
\text { VI }\end{array}$ \\
\hline Crianças & 58 & 41 & 29 & 49 & 56 & 23 \\
\hline Acadêmicos Auxiliares & 58 & 57 & 76 & 45 & 71 & 08 \\
\hline Bolsistas & 01 & 03 & 06 & 03 & 10 & 20 \\
\hline Ministrantes & $0 *$ & 06 & $0 *$ & 07 & 19 & 04 \\
\hline Coordenadora & $15^{*}$ & 04 & $10 *$ & 0 & 02 & 0 \\
\hline Pai do Aluno & 0 & 0 & 0 & 0 & 0 & 10 \\
\hline TOTAL & 132 & 111 & 121 & 104 & 158 & 65 \\
\hline
\end{tabular}

* Nas aulas dos Semestres I e III, a coordenadora foi quem ministrou e na aula do Semestre VI o pai da criança atuou como acadêmico.

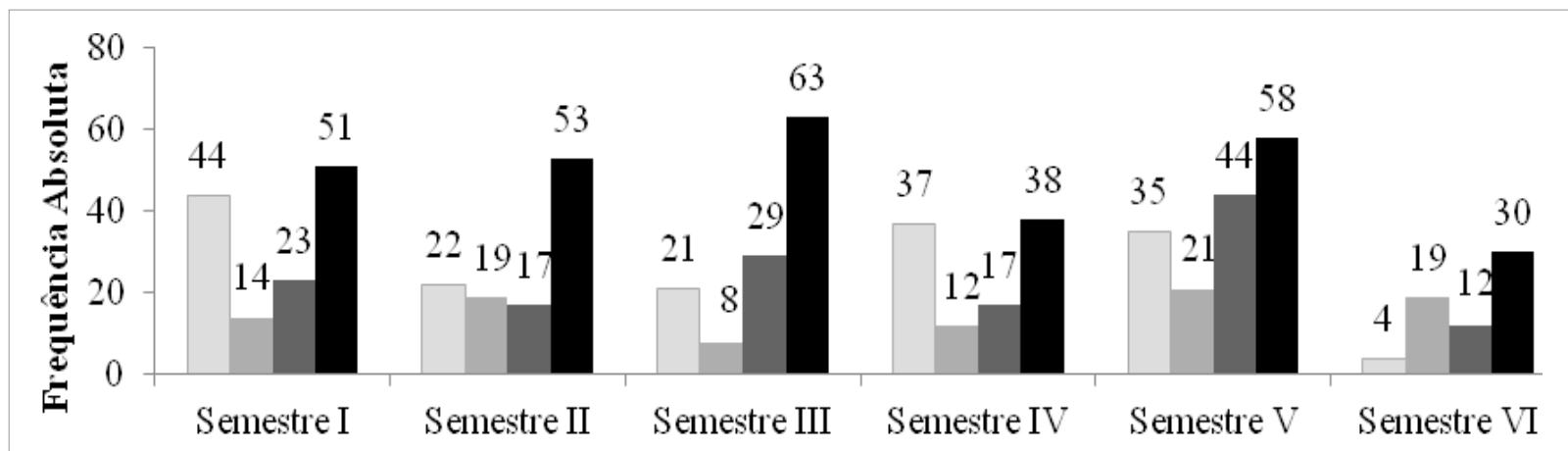

$\square$ Interação iniciada pela criança em direção à seus pares

- Interação iniciada pelos pares em direção à criança

- Interação iniciada pela criança em direção aos adultos

- Interação iniciada pelos adultos em direção à criança

Figura 2 - Direção das interações sociais ocorridas nas aulas. 
razão de suas características pessoais atrativas e que seus atributos pessoais são considerados demandas positivas para a socialização. ${ }^{17}$ Já, a criança inicia as interações sociais em direção a seus amigos em decorrência da amizade recíproca. Os estudos de Nangle et al. ${ }^{34}$ relatam que, quando a amizade é correspondida, o sentimento de solidão das crianças com deficiência diminui.

Por fim, faz-se necessário mencionar que o envolvimento de crianças sem deficiência é de grande valia para o desenvolvimento global de crianças com deficiência. Nas aulas dos Semestres I, II e III, havia duas crianças sem deficiência, irmãs de alunos engajados no AMA. A importância da interação entre crianças com deficiência e seus pares sem deficiência no ajustamento social tem sido relada em estudos com crianças em idade escolar. ${ }^{36}$

\section{CONSIDERAÇÕES FINAIS}

A partir dos assuntos problematizados até o presente momento, pode-se, ainda, enfatizar as questões norteadoras desse trabalho, quais sejam: tempos de aula e de engajamento e também a melhora motora e social.

Primeiramente, é necessário esclarecer as funções dos educadores que, por sua vez, devem planejar as aulas previamente a fim de que a aula não resulte em um conjunto de atividades sem relação entre si. Assim, há maior facilidade em se otimizar os tempos das aulas e auxiliar na organização dos materiais necessários. Também cabe ao educador elaborar atividades que favoreçam o desenvolvimento da criança e, ainda, que respeitem suas fases de desenvolvimento.

Durante os três anos analisados, sobreleva-se a evolução do aluno. Nos primeiros semestres, os profissionais precisaram conhecê-lo para, assim, identificar suas possibilidades. À medida que os profissionais aprenderam a maneira de trabalhar com o aluno, foi possível auxiliá-lo, com maior qualidade, a fim de fazê- lo realizar as tarefas propostas pelos ministrantes. Ou seja, a partir do momento que se conhece a criança e sua fase de desenvolvimento, as adequações são fornecidas de modo mais eficiente, oportunizando o maior engajamento nas atividades.

Nesse sentido, salienta-se que fazer amigos e se divertir nas aulas de Educação Física foram elementos fundamentais que interferiram no desenvolvimento da criança. Ademais, a compreensão da importância da atividade física por parte da família do aluno e, acima de tudo, o comprometimento da mesma contribuíram para o desenvolvimento da criança.

Além disso, os profissionais interagem com o aluno com o principal propósito de auxiliá-lo e, desta maneira, facilitam as interações sociais da criança com os seus pares. Afinal, o aluno é acompanhado a realizar todas as atividades propostas, consequentemente fica próximo do grupo constantemente. Nesse sentido, torna-se parte do grupo. Seus colegas o reconhecem como amigo e esse sentimento é mútuo.

Em razão das características da ECNE, algumas adequações serão sempre as mesmas, como o empurrar a cadeira de rodas. Por outro lado, em virtude da melhora motora ocasionada pela prática regular de atividade física, a criança conseguiu expressar suas vontades com maior facilidade, sendo assim, toca a cadeira de rodas e aponta para pessoas e/ou lugares de seu interesse com maior frequência.

Por fim, sugerem-se mais estudos relacionados à educação inclusiva a fim de que se observe como ocorre a participação de crianças com deficiências em aulas de Educação Física nas turmas regulares e também as interações sociais entre as crianças com deficiência e seus pares sem deficiência.

\section{REFERÊNCIAS}

1. Rosenbaum P. Cerebral palsy: What parents and doctors want to know. Br Med J 2003;326(7396):970-4. DOI: 10.1136/bmj.326.7396.970.

2. Jones MW, Morgan E, Shelton JE, Thorogood C. Cerebral Palsy: Introduction and Diagnosis (Part I). J Pediatr Health Care 2007;21(3):146-52. DOI: 10.1016/j.pedhc.2006.06.007.

3. Pakula AT, Braun KVN, Yeargin-Allsopp M. Cerebral Palsy: Classification and Epidemiology. Phys Med Rehabil Clin N Am 2009;20(3):425-52. DOI: 10.1016/j.pmr.2009.06.001.

4. Maclennan AH, Franzcog SCT, Fracp JG. Cerebral palsy: causes, pathways, and the role of genetic variants. Am J Obstet Gynecol 2015;213(6):779-88. DOI: 10.1016/j.ajog.2015.05.034.

5. Yeates KO, Bigler ED, Dennis M, Gerhardt CA, Rubin $\mathrm{KH}$, Stancin T, Taylor HG, Vannatta K. Social outcomes in childhood brain disorder: A heuristic integration of social neuroscience and developmental psychology. Psychol Bull 2007;133(3):535-56. DOI: 10.1037/0033-2909.133.3.535.

6. Enkelaar L, Ketelaar M, Gorter JW. Association between motor and mental functioning in toddlers with cerebral palsy. Dev Neurorehabil 2008;11(4):276-82. DOI: 10.1080/17518420802581164.

7. Law M, King G, King S, Kertoy M, Hurley P, Rosenbaum $P$, Young N, Hanna S. Patterns of participation in recreational and leisure activities among children with complex physical disabilities. Dev Med Child Neurol 2006;48(5):337-42. DOI: 10.1017/S0012162206000740.

8. Nadeau L, Tessier R. Social adjustment of children with cerebral palsy in mainstream classes: peer perception. Dev Med Child Neurol 2006;48(5):331-6. DOI: 10.1017/ S0012162206000739.

9. Whittingham K, Fahey M, Rawicki B, Boyd R. The relationship between motor abilities and early social development in a preschool cohort of children with cerebral palsy. Res Dev Disabil 2010;31(06):1346-51. DOI: 10.1016/j.ridd.2010.07.006.

10. Voorman JM, Dallmeijer AJ, Van Eck M, Schuengel C, Becher JG. Social functioning and communication in children with cerebral palsy: association with disease characteristics and personal and environmental factors. Dev Med Child Neurol 2010;52(5):441-7. DOI: 10.1111/1460-6984.12138.

11. Schmitt BD, Bataglion GA, Zuchetto AT, Nasser JP. Interações sociais de crianças com deficiência: Peculiaridades do conceito Halliwick. Kinesis 2015;33(1):55-70. DOI: $10.5902 / 2316546418227$.

12. Hogan A, McLellan L, Bauman A. Health promotion needs of young people with disabilities: A population study. Disabil Rehabil 2000;22(08):352-7. DOI: 10.1080/096382800296593.

13. Longmuir $\mathrm{P}, \mathrm{Bar}-\mathrm{Or} \mathrm{O}$. Factors influencing the physical activity levels of youths with physical and sensory disabilities. Adapt Phys Activ Q 2000;17(1):40-53.

14. Whitt-Glover M, O'Neill K, Stettler N. Physical activity patterns in children with and without Down syndrome. 
Pediatr Rehabil 2006;09(02):158-64. DOI: 10.1352/19349556-50.2.109.

15. Rimmer JH, Rowland JL, Yamaki K. Obesity and Secondary Conditions in adolescents with disabilities: Addressing the needs of an underserved population. J Adolesc Health 2007;41(3):224-9. DOI: 10.1016/j.jadohealth.2007.05.005.

16. França C, Zuchetto AT. Comparação do Comportamento Social de um Portador de deficiência Mental antes e durante um quadro depressivo, em sessões de atividade motora adaptada: um estudo de caso. Anais do XIII Congresso Brasileiro de Ciências do Esporte. Caxambu/MG; 2003 set.

17. Zuchetto AT. A trajetória de Laila no AMA: Histórias entrelaçadas. [Tese de Doutorado] Campinas, SP: Programa de Pós-graduação Saúde da Criança e do Adolescente, Faculdade de Ciências Médicas, Unicamp, 2008, f. 210.

18. Schmitt BD, Santos B, Siqueira MGA, Miranda TB, Zuchetto AT. Educação Física Adaptada: análise da distribuição dos tempos em aulas. Lecturas Educación Física y Deportes 2011;15(152).

19. Zuchetto AT, França C, Nasser J. Adequações, dificuldades e auxílios necessários para o engajamento de um autista em atividade motora. Lecturas Educación Física y Deportes. 2011;16(158).

20. Schmitt BD, Zuchetto AT. Engagement of a child with cerebral palsy in a Motor Activity Adapted Program. The FIEP Bulletin 2014;84:389-92.

21. Schmitt BD, Zuchetto AT, Nasser JP. Engagement of children with disabilities in festive events in an Adapted Motor Activity Program. The FIEP Bulletin 2015;85:136-9. DOI: 10.16887/85.a1.32.

22. Schmitt BD, Bataglion GA, Zuchetto AT, Nasser JP. Halliwick concept and engagement of children with disabilities. The FIEP Bulletin 2015;85:164-8. DOI: 10.16887/85.a1.39.

23. Zuchetto AT. Relatório AMA - Atividade Motora Adaptada. Relatório DEF/CDS/UFSC, Florianópolis, SC, 2001.

24. Krebs RJ. Considerações organizacionais para a Educação Física nas séries iniciais do ensino fundamental. Cinergis 2000;1(1):1-38.

25. Winnick JP. Educação Física e Esportes Adaptados. $3^{a}$ edição: Barueri, Manole; 2004, 553p.

26. Sherril C. Adapted physical activity, recreation and sport crossdisciplinary and lifespan. 6 edição: Boston, MA: William C. Brown/McGraw Hill, 2004, 784p.

27. Schmitt BD, Zuchetto AT. Evolução do engajamento de uma criança com paralisia cerebral e com deficiência auditiva em atividades cantadas. Lecturas Educación Física y Deportes 2011;16(161).

28. Winnick JP. Adapted physical education and sport. $5^{\mathrm{a}}$. ed. Champaign: Human Kinectics; 2011. 656p.

29. Block ME, Krebs PL. An altemative to the continuum of least restrictive environments: A continuum of support to regular physical education. Adapt Phys Activ Q 1992;9(2):97-113.

30. Block ME, Zeman R. Including Students with disabilities in regular physical education: Effects on nondisabled children. Adapt Phys Activ Q 1996;13(1):38-49.

31. Rimmer JH. Physical fitness levels of persons with cerebral palsy. Dev Med Child Neurol 2001;43(03):208-12. DOI: 10.1111/j.1469-8749.2001.tb00189.x

32. Maher CA, Williams MT, Olds T, Lane AE. Physical and sedentary activity in adolescents with cerebral palsy. Dev Med Child Neurol 2007;49(06):450-7. DOI: 10.1111/j.14698749.2007.00450.x

33. Smits D, Gorter JW, Ketelaar M, Van Schie PE, Dallmeijer AJ, Lindeman E, Jongmans MJ. Relationship between gross motor capacity and daily-life mobility in children with cerebral palsy. Dev Med Child Neurol 2010;52(3):60-6. DOI: 10.1111/j.1469-8749.2009.03525.x.

34. Wilson PE. Exercise and sports for children who have disabilities. Phys Med Rehabil Clin N Am 2002;13(04): 907-923. DOI: 10.1016/S1047-9651(02)00030-X

35. Nangle DW, Erdley CA, Newman JE, Mason CA, Carpenter EM. Popularity, friendship quantity, and friendship quality: interactive influences on children's loneliness and depression. J Clin Child Adolesc Psychol 2003;32(4):546-55. DOI: 10.1207/S15374424JCCP3204_ 7.

36. Hay DF, Payne A, Chadwick A. Peer relation in childhood. J Child Psychol Psychiatry 2004;45(1):84-108. DOI: 10.1046/j.0021-9630.2003.00308.x.

Como citar: SCHMITT, Beatriz Dittrich; ZUCHETTO, Angela Teresinha; NASSER, John Peter. Influência da Educação Física Adaptada inclusiva no desenvolvimento global de uma criança com deficiências multiplas durante três anos. Cinergis, Santa Cruz do Sul, v. 17, n. 1, mar. 2016. ISSN 2177-4005. Disponível em: <https://online.unisc.br/seer/index.php/cinergis/article/ view/7084>. Acesso em: . doi:http://dx.doi.org/10.17058/cinergis.v17i1.7084. 